\title{
Performance appraisal as an antecedent to innovation: An analysis of its importance relative to other human resource practices
}

\begin{tabular}{|c|c|}
\hline \multicolumn{2}{|c|}{$\begin{array}{l}\text { Authors: } \\
\text { Navin G. Matookchund }{ }^{1} \text { (D) } \\
\text { Renier Steyn }{ }^{2} \text { (1) }\end{array}$} \\
\hline \multicolumn{2}{|c|}{$\begin{array}{l}\text { Affiliations: } \\
{ }^{1} \text { Graduate School of Busir } \\
\text { Leadership, University of } \\
\text { South Africa, Pretoria, } \\
\text { South Africa }\end{array}$} \\
\hline \multicolumn{2}{|c|}{$\begin{array}{l}{ }^{2} \text { Department of Leadership } \\
\text { and Organisational } \\
\text { Behaviour, Graduate School } \\
\text { of Business Leadership, } \\
\text { University of South Africa, } \\
\text { Pretoria, South Africa }\end{array}$} \\
\hline \multicolumn{2}{|c|}{$\begin{array}{l}\text { Corresponding author: } \\
\text { Navin Matookchund, } \\
\text { navin.matookchund@sasol. } \\
\text { com }\end{array}$} \\
\hline \multicolumn{2}{|c|}{$\begin{array}{l}\text { Dates: } \\
\text { Received: } 20 \text { May } 2019 \\
\text { Accepted: } 29 \text { Aug. } 2019 \\
\text { Published: } 29 \text { Oct. } 2019\end{array}$} \\
\hline \multicolumn{2}{|c|}{$\begin{array}{l}\text { How to cite this article: } \\
\text { Matookchund, N.G., \& } \\
\text { Steyn, R. (2019). Performance } \\
\text { appraisal as an antecedent to } \\
\text { innovation: An analysis of } \\
\text { its importance relative to } \\
\text { other human resource } \\
\text { practices. SA Journal } \\
\text { of Human Resource } \\
\text { Management/SA Tydskrif vir } \\
\text { Menslikehulpbronbestuur, } \\
\text { 17(0), a1219. https://doi.org/ } \\
\text { 10.4102/sajhrm.v17i0.1219 }\end{array}$} \\
\hline \multicolumn{2}{|c|}{$\begin{array}{l}\text { Copyright: } \\
\text { ( 2019. The Authors. } \\
\text { Licensee: AOSIS. This w } \\
\text { is licensed under the } \\
\text { Creative Commons } \\
\text { Attribution License. }\end{array}$} \\
\hline \multicolumn{2}{|l|}{ Read online: } \\
\hline 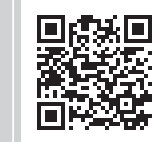 & $\begin{array}{l}\text { Scan this QR } \\
\text { code with your } \\
\text { smart phone or } \\
\text { mobile device } \\
\text { to read online. }\end{array}$ \\
\hline
\end{tabular}

Orientation: Innovation is essential to organisational survival, and several studies have shown that performance appraisals (PAs) contribute to innovation.

Research purpose: The purpose of this study was to examine the importance of PA as an antecedent to innovation relative to other human resource practices (HRPs).

Motivation for the study: The specific HRP drivers of innovation among employees and across organisations are not well specified, hindering appropriate resource allocation.

Research approach/design and method: The PA-innovation link was investigated among 3180 employees across 53 South African organisations, utilising a cross-sectional survey design involving quantitative data, and focusing on correlation and regression analyses.

Main findings: Human resource practices accounted for approximately $10 \%$ of the variance in innovation when considering individual employees. Performance appraisal was neither a common nor a unique predictor of innovation. When focusing on the link across organisations, a significant HRPs-innovation link was established in approximately $60 \%$ of organisations, with PA playing a significant role as the predictor of innovation in 10 (out of 53) organisations.

Practical/managerial implications: Other HRPs, specifically supervisor support and staffing, played a much bigger role than PA in driving innovation of individuals, also across organisations. This specifies the relative importance of PA amongst other HRPs.

Contribution/value-add: General managers, human resource practitioners and researchers can now use data-driven evidence to select specific HRPs which significantly enhance innovation among employees and across organisations.

Keywords: human resource models; human resource practices; innovation; performance appraisal; South Africa.

\section{Introduction}

Innovation is essential for an organisation to increase its performance and competitive position globally (Abbaspour, 2015; Le Bas \& Lauzikas, 2009; Ling \& Nasurdin, 2011). Furthermore, innovation leads to competitive advantage (Aryanto, Fontana, \& Afiff, 2015; Subramaniam \& Youndt, 2005). Organisational survival in today's harsh economic climate is dependent on innovation (Abbaspour, 2015; Ceylan, 2013; Runfeng, 2011). In addition, innovation is vital for organisational advancement, success and survival (Chang, Gong, \& Shum, 2011; Maier, Brad, Nicoara, \& Maier, 2014).

Although innovation is important, it is not possible to achieve innovation without allocating human resources to innovation initiatives and introducing suitable human resource practices (HRPs) (Kim \& Choi, 2014; Le Bas \& Lauzikas, 2009). Also, according to Chen and Huang (2009), and Cooke and Saini (2010), it is important that HRPs should be adopted to implement innovation within an organisation.

In numerous studies, it has been empirically established that performance appraisal (PA) (Aktharsha \& Sengottuvel, 2016; Dalota \& Perju, 2010; Runfeng, 2011), along with other HRPs (Aktharsha \& Sengottuvel, 2016; Chang et al., 2011; Dalota \& Perju, 2010), is an antecedent to innovation.

Referring to specific practices, numerous studies have shown that HRPs, namely PA, employee participation, and rewards, contribute to innovation (Dalota \& Perju, 2010; Jimenez-Jimenez \& 
Sanz-Valle, 2005; Laursen \& Foss, 2003). On the other hand, Aktharsha and Sengottuvel's (2016) research revealed that three main HRPs - PA, recruitment and selection, and compensation and rewards are significant predictors of knowledge sharing. Many studies have empirically established that knowledge sharing plays an important role in predicting innovation (Aktharsha \& Sengottuvel, 2016; Subramaniam \& Youndt, 2005; Wu \& Lee, 2013). Wu and Lee (2013) further suggest that training and development, and compensation and rewards significantly affect knowledge sharing and innovation. Kim and Choi (2014) also found that PA, reward and training enhance affective commitment, which, in turn, contributes to innovation.

From the aforementioned discussion, it is evident that there is no consensus on the particular practices that drive innovation. More so, the relative importance of the different practices is not well known. It is also not surprising that much of the research on HRPs and innovation is conducted primarily within the Western context (Al-Bahussin \& ElGaraihy, 2013; Katou, 2008). Evidence of empirical research on the HRP-innovation relationship is lacking within the South African context. Within the latter context, the specific drivers of innovation among employees and across organisations are not well specified. This study therefore attempted to create a clarity on the specific human resource drivers of innovation and contextualise the research within the South African context.

Although several empirical studies (e.g. Al-Bahussin \& ElGaraihy, 2013; Aryanto, et al., 2015; Katou, 2008) have uncovered a link between HRPs and innovation, most of them were often single-company or single-industry driven and undertaken with relatively small samples. This study uses a relatively large sample $(N>3000)$ to investigate the relationship both among employees and within organisations.

The majority of the research (e.g. Le Bas \& Lauzikas, 2009) has been limited to examining HRPs as a single concept rather than as individual practices in their own right. Becker and Huselid (1998), in their seminal paper, along with others, such as Tang, Wei, Snape and Ng (2015), preferred a focus on a single concept. This study attempted to include several other HRPs in the model. Madmoli (2016), Steyn (2012) and Sun, Aryee and Law (2007) preferred to focus on multiple HRPs. The focus of this research was on the individual practices, particularly PA, as this allows managers to make informed decisions about which practice to focus on, rather than improving human resources in general.

\section{Research problem}

Many studies (e.g. Al-Bahussin \& El-Garaihy, 2013; Aryanto et al., 2015; Katou, 2008) have shown that HRPs contribute to innovation. However, appropriate quantification with regard to PA as an antecedent to innovation, relative to an array of individual HRPs, both among employees and within South African organisations, is not sufficiently investigated. Without this nuance of information on the individual HRP-innovation relationship, managers and human resource practitioners may inappropriately allocate resources to specific HRPs, thus hindering organisational success.

\section{Aim}

The aim of this article was to investigate the importance of PA as an antecedent to innovation, relative to an array of individual HRPs, both among employees (in general) and within (specific) South African organisations.

\section{Literature review}

There is widespread interest in human resources, and practitioners and researchers often debate the available HRP literature (Keir, 2016). According to Al-Bahussin and ElGaraihy (2013), human resources are important to organisations. Ceylan (2013), Cooke and Saini (2010) and Hayton (2005) indicate that research on HRPs and innovation has increased considerably over the past few decades. Similarly, according to Delery and Gupta (2016) and Hayton (2005), the number of studies on HRPs has increased dramatically in the last two decades. The number of journals dedicated to human resource management has increased substantially in the past few years, both in South Africa and internationally.

Effective human resources have positive effects on performance in general. Most successful organisations exploit HRPs as tools to improve effectiveness and performance (DeNisi \& Pritchard, 2006; Esu \& Inyang, 2009). HRPs contribute to continuous improvement and success (Ahmed, Mohammad, \& Islam, 2013; Hayton, 2005), and in addition, HRPs are employed in organisations to serve many purposes. Delery and Doty (1996) and Delery and Gupta (2016) argue that HRPs are important in trying to achieve organisational goals.

Human resources management consists of many practices. Edralin (2010) suggests that HRPs include PA, recruiting, compensation, selecting, training and development, and employee relations. Cascio (2010), meanwhile, suggests that staffing, information sharing, PA, promotion systems, incentive systems and grievance procedures are the best HRPs for 21st century firms. Madmoli (2016) also argues that selection, training, job evaluation, rewarding, participation, recruiting, and information sharing are effective HRPs. As a final example, Sun et al. (2007) indicate that job security, training, promotion, appraisal and career paths are highperformance HRPs.

Several studies have empirically established the HRPinnovation link (Al-Bahussin \& El-Garaihy, 2013; Aryanto et al., 2015; Katou, 2008). Noe, Hollenbeck, Gerhart and Wright (2008) also point out that HRPs have been recognised to improve organisational performance by contributing to innovation, satisfaction and productivity. Laursen and Foss (2003), for example, found that seven out of nine HRPs lead to innovation. Dalota (2013) and Looise and Van Riemsdijk 
(2004) indicate that HRPs contribute to innovation, while Jimenez-Jimenez and Sanz-Valle (2005) and Ling and Nasurdin (2011) suggest that HRPs have a major impact on innovation.

Theoretically, the focus on certain practices is explained. Organisations routinely utilise a combination of HRPs, or individual HRPs, to either directly or indirectly gain competitive advantage (Delery \& Doty, 1996; Edralin, 2010; Ling \& Nasurdin, 2011). As stated above, however, no consensus on the particular practices that drive innovation is available, particularly within the South African context. It is, however, not clear whether HRPs are an effective driver of innovation in all organisations. The three major approaches to understanding human resource management are the universalistic, contingency and configurational perspectives (Delery \& Doty, 1996; Katou \& Budhwar, 2007).

The universalistic perspective theorises that some HRPs are generally superior to others in all organisations under any conditions (Delery \& Doty, 1996; Jeong \& Choi, 2016; Katou, 2008). This suggests that organisations that accept these best practices achieve superior results (Delery \& Doty, 1996; Katou, 2008; Steyn, 2012) and that strategy and HRPs are equally free in influencing organisational performance (Claus, 2003; Lengnick-Hall, Lengnick-Hall, Andrade, \& Drake, 2009).

The contingency perspective theorises that the choice of a certain set of HRPs is reliant on strategy (Katou, 2008; Lengnick-Hall et al., 2009). Katou and Budhwar (2007) state that there needs to be a fit between organisational and human resource strategy to influence performance. Katou's (2008) research suggests that a contingency perspective may mean that an innovation strategy determines HRPs, or that human resource policy determines an innovation strategy for an organisation. Meanwhile, the choice of innovation strategy for organisations depends on a specific bundle of HRPs (Dalota \& Perju, 2010; Jimenez-Jimenez \& Sanz-Valle, 2005; Laursen \& Foss, 2003).

The configurational perspective, according to Jeong and Choi (2016) and Lengnick-Hall et al. (2009), theorises that groupings of certain HRPs, rather than individual HRPs, increase organisational performance as some practices reinforce one another. This implies that there are particular combinations of HRPs that are the most suitable for improving performance. Delery and Doty (1996) opine that, for the configurational perspective, there should be both internal consistency of HRPs (horizontal fit) and congruence of human resource systems and other organisational features (vertical fit).

Considering the three theoretical perspectives, all HRPs uniformly correlating with innovation in all 53 organisations would provide proof of the HRP-innovation link being universalistic. Should the relationship be a good fit for the configurational perspective, it might be expected that the results show specific patterns in the way in which HRPs correlate with innovation across organisations. Unfortunately, confirmation of a contingency perspective would require data on the strategic positions of the different organisations to have been gathered, but this was not done. The contingency perspective could, therefore, not be investigated.

\section{Research design Research approach}

A cross-sectional survey design, which concentrated on quantitative data, was employed. Bryman (2012) and Punch (1998) suggest that a quantitative research design procedure is suitable for this study as it readily allows the establishment of relationships between variables.

The data utilised were gathered as part of a research project led by the second author of the study. The sample of organisations was a convenience sample. Once the organisations had been identified, respondents were chosen at random from the organisation's employee records. Ultimately, the data comprised 3180 employees employed by 53 organisations within South Africa, representing the private sector, parastatals and government departments.

\section{Measuring instruments}

The HRP scale (Nyawose, 2009) and the innovative work behaviour (IWB) questionnaire (De Jong \& Den Hartog, 2010) were employed in this study.

\section{Human resource practices}

The HRP scale by Nyawose (2009) was employed to assess the apparent effectiveness of HRPs. This questionnaire comprised 21 statements, arranged according to seven HRPs (training and development, compensation and rewards, PA, supervisor support, staffing, diversity management, and communication and information sharing) and with each HRP area containing three statements (Table 1). Respondents were invited to indicate their perceptions for each item on a fivepoint scale as follows: 1 (strongly disagree), 2 (disagree), 3 (not sure - uncertain), 4 (agree) and 5 (strongly agree). The lowest possible score would be 3 , and the highest possible score would be 15, per HRP. Also, in this study, the highest score obtained per HRP was 15, and the lowest score was 3 . A high score would mean that respondents view HRPs as effective and a low score would show dissatisfaction with HRPs (Steyn, 2012). Nyawose (2009) reports reliability scores ranging from 0.74 to 0.93 for these HRPs, plus significant correlations (in the expected direction), with outcomes such as occupational commitment and turnover intentions. Furthermore, Steyn (2012) and Steyn and Grobler (2014) report Cronbach's alphas of 0.87, 0.74, 0.81, 0.75 and 0.88 for five HRPs, namely, compensation and rewards, staffing, PA, diversity management, and training and development, respectively. In the same study by Steyn and Grobler (2014), the results indicated that the HRP scale is both reliable and valid. To further support the validity of the HRP scale, Steyn (2012) found that HRPs correlated positively with job satisfaction and negatively with the intention to quit. 
TABLE 1: Constructs, items of the human resource practice scale, reliability coefficients and correlations between constructs and innovation.

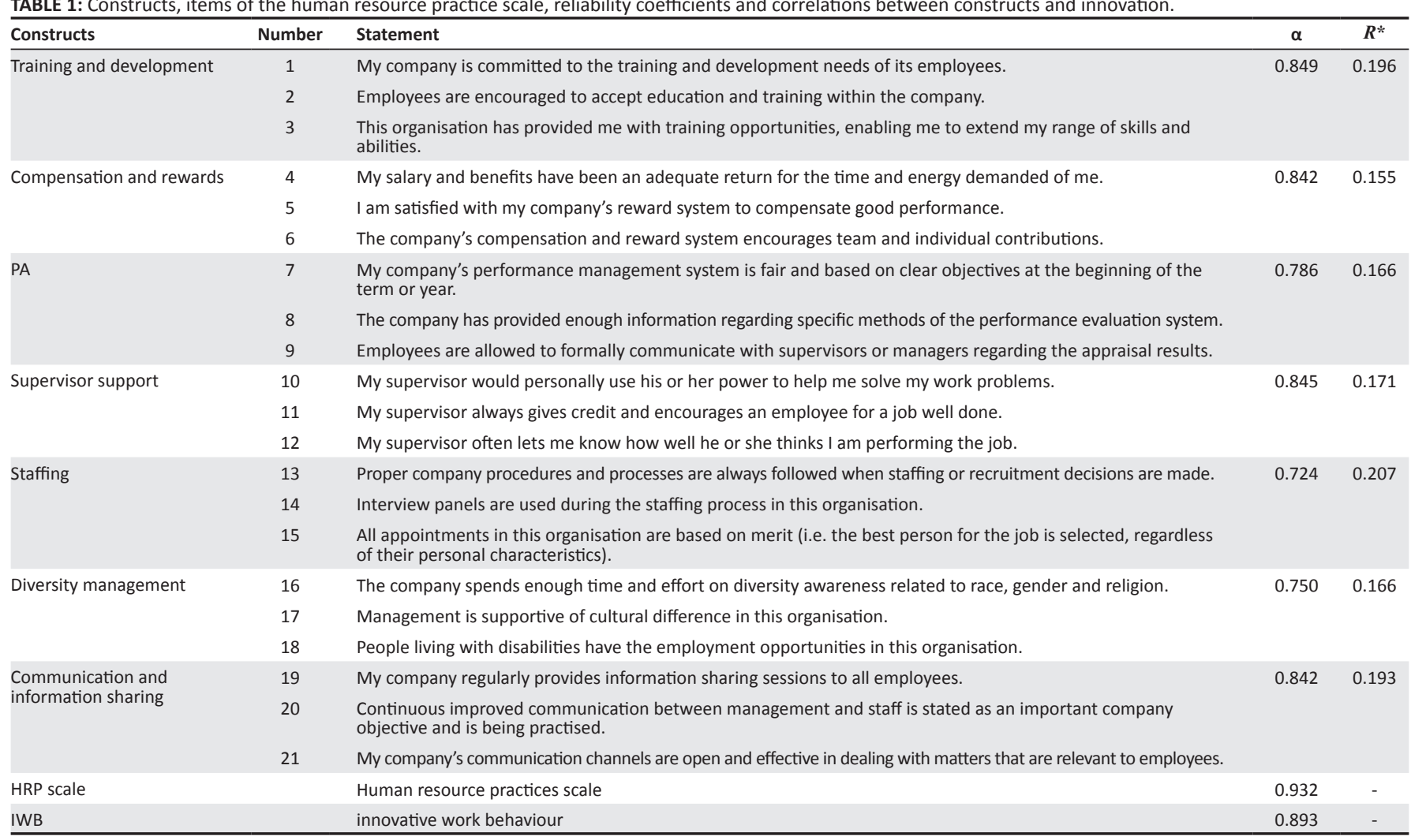

HRP, human resource practices; IWB, innovative work behaviour; PA, performance appraisal.

All instruments have a Cronbach's alpha above 0.7 , which indicates that the reliability is acceptable.

*All correlations are significant at the 0.01 level (2-tailed).

\section{Innovative work behaviour}

The IWB questionnaire from De Jong and Den Hartog (2010) was selected to measure IWB. It consists of 10 questions. The questionnaire had to be modified for this study. No measurement scale was provided in the De Jong and Den Hartog's (2010) article. A scale was therefore introduced, ranging from (0) never to (6) always. The lowest score obtained was 0 , and the highest score obtained was 60 . The following is a question from the original IWB questionnaire: ' $h$ h]ow often does this employee ... pay attention to issues that are not part of his daily work?' (De Jong \& Den Hartog, 2010, p. 29). This format did not suit our study, which emphasises the views of individuals concerning their IWB. All 10 items of the questionnaire were thus amended to begin with 'as an employee how often do you ...' instead of 'how often does this employee ...'. De Jong and Den Hartog (2010) reported that the instrument is adequately reliable (Cronbach's alpha $>0.7$ ). According to De Jong and Den Hartog (2010), there is clear evidence that employee's innovation outputs $(R=0.35$; $p<0.01)$, participative leadership $(R=0.25 ; p<0.01)$ and external work contacts $(R=0.27 ; p<0.01)$ correlate with IWB, and this points to good criterion validity. The adapted version of the instrument was used for this study.

\section{Statistical analysis}

The Statistical Package for Social Science (SPSS) was used to conduct all statistical analysis, except for the confirmatory factor analysis (CFA), which was performed using the lavaan package.
Firstly, frequencies were computed to provide biographical data on respondents. Then, Cronbach's alphas were calculated to confirm the reliability of all instruments. Based on recommendations from Nunnally (1978) and Ursachi, Horodnic and Zait (2015), all instruments with a Cronbach's alpha score of more than 0.7 were considered to possess adequate reliability.

With regard to the validity of the HRP scale, CFA was used for the analysis. A seven-factor model of training and development, compensation and rewards, PA, supervisor support, staffing, diversity management, and communication and information sharing was tested. Maximum likelihood estimation was selected, and the latent factors were standardised to allow free estimation of all factor loadings. Awang (2012) and Hair, Black, Babin and Anderson (2009) suggest that the model fit is acceptable when the TuckerLewis index (TLI) is greater than 0.9, the comparative fit index (CFI) is greater than 0.9 and the root mean square error of approximation (RMSEA) is less than 0.05 .

With regard to the validity of the IWB scale, as IWB was defined as a unidimensional construct (De Jong \& Den Hartog, 2010), the validity was only tested through specifying the amount of variance declared by the single factor. Bateman and Crant (1993) report a declared variance of around 0.30 as acceptable, when defending their unidimensional construct, and this guideline was also followed in this study. 
Correlation coefficients were computed between HRPs (as a single construct) and for innovation behaviour, both among employees and across organisations. Pearson's correlations (2-tailed) were utilised to define the extent of the relationship between the variables. These correlations were considered statistically significant at the 0.01 level. Based on the guidelines set out by Cohen (1988), the calculation of the practical significance of the alphas is as follows: $R$ greater than 0.5 is deemed 'large', $R$ greater than 0.3 but less than 0.5 is deemed 'medium' and $R$ greater than 0.1 but less than 0.3 is deemed 'small'.

Regression analyses were performed at the employee and organisational level. Firstly, these analyses were executed to compute how the different subscales of HRPs predict IWB. Then, the subscales of HRPs, which significantly and uniquely predict IWB, were identified. The 'Enter' option in SPSS was selected for the regression analysis where all the HRPs were regressed to predict innovation. The 'Stepwise' option in SPSS was then selected for the regression analysis in order to identify the individual HRPs which contribute uniquely and significantly to predicting innovation. Finally, following the procedure set out by Pallant (2013) and Peck and Devore (2011), the coefficient of determination in innovation was calculated by multiplying the $R^{2}$ values by 100 .

When considering the models across organisations, validation of a universalistic model would be evident when all organisations display similar relationships between HRPs and innovation, with little variation between organisations. Another indicator of the universalistic perspective would be whether $R^{2}$ was significant for the HRP-innovation link in all organisations. The same HRP subscales should relate to innovation across organisations, and the relative contribution of antecedents should be ranked similarly across organisations.

Validation of a configurational model would consist of establishing unique sequences in which HRPs relate to innovation. Validation of a configurational model would be seen if particular combinations of subscales frequently predict innovation, or should patterns of antecedents predict innovation significantly.

\section{Ethical considerations}

Ethical approval to conduct the study was obtained from the University of South Africa, School of Business Leadership Research Ethics Review Committee, (ethics clearance number: 2018_SBL_DBL_003_SD). The data were gathered as per the ethics guidelines of the University of South Africa (UNISA), and authorisation was obtained from the UNISA Research Ethics Review Committee to use the data as secondary data.

\section{Results \\ Biographical data}

The sample consisted of 3180 employees drawn from 53 organisations within South Africa.

\section{Gender}

The respondents were grouped into two gender groups. The 2016 Quarterly Labour Force Survey points out that gender demographics across South Africa is almost equally distributed (Statistics South Africa, 2016) and is closely aligned to the gender distribution in this study. A total of $1771(55.7 \%)$ respondents logged their gender as male and $1372(43.1 \%)$ recorded their gender as female, while for 37 $(1.2 \%)$ respondents the data were missing.

\section{Race}

The respondents were grouped into four race groups, and these data are aligned to the Quarterly Labour Force Survey in the sense that, in the larger South African context, black people make up the largest workforce group, followed by white people, mixed race people and Asian people in descending order (Statistics South Africa, 2016). A total of 263 (8.3\%) respondents were Asian people, 1830 (57.5\%) were black people, 263 (8.3\%) were mixed race people and $787(24.7 \%)$ were white people, while for 37 (1.2\%) respondents the data were missing.

\section{Age}

The 2016 Quarterly Labour Force Survey indicates that the age of the South African workforce ranges from 15 to 64 years (Statistics South Africa, 2016) and this is closely aligned to the respondents whose ages ranged from 20 to 72 years, with a mean of 37.81 and a standard deviation of 9.10 years.

\section{Educational qualifications}

A total of 934 (29.4\%) respondents held a bachelor's degree or higher, 1274 (40.1\%) possessed a diploma, 789 (24.8\%) had matriculation and $143(4.5 \%)$ had less than 12 years of schooling, while for $40(1.3 \%)$ respondents the data were missing.

\section{Management and tenure}

Those in management positions totalled 1156 (36.4\%), and those in non-management positions represented 1983 $(62.4 \%)$, while for $41(1.3 \%)$ respondents the data were missing. As far as tenure at their current employers is concerned, this varied between 1 month and 42 years, with a mean of 8.49 and a standard deviation of 7.45 years.

\section{Economic sector}

A total of 1981 (62.3\%) organisations fell within the private sector, $480(15.1 \%)$ were parastatal and 719 (22.6\%) were government departments, for example, the Department of Trade and Industry, the Department of Tourism and so on.

From the biographical data presented above, it is evident that the respondents represent a broad cross-section of the South African workforce.

\section{Reliability}

The HRP scale consists of seven constructs, and each construct consists of three items (Table 1). Cronbach's alphas for the 
TABLE 2: Total sample correlation and regression analyses $(N=3180)$

\begin{tabular}{lccl}
\hline Measure of innovation & HRP scale (total score) and innovation & All subscales of the HRP scale and innovation & All subscales of the HRP scale and innovation (Optimal model) \\
\hline IWB & $R=0.319 ; p<0.01$ & $R_{\text {adjusted }}^{2}=0.107 ; p<0.01$ & $\begin{array}{l}R_{\text {adjusted }}^{2} 0.107 ; p<0.01 ; \\
\text { Subscales: Staffing, training and development, communication } \\
\text { and information sharing, compensation and rewards, and } \\
\text { supervisor support }\end{array}$ \\
\hline
\end{tabular}

HRP, human resource practices; IWB, innovative work behaviour.

TABLE 3: Organisation specific correlation and regression analyses ( $N=60$ per organisation).

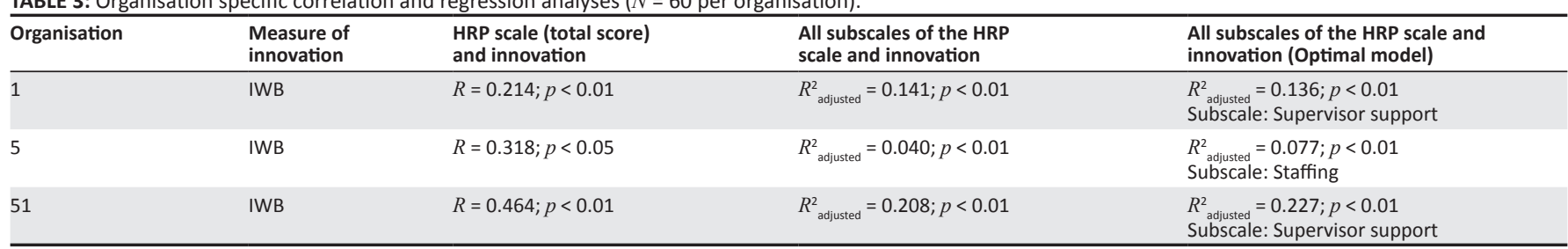

HRP, human resource practices; IWB, innovative work behaviour.

individual constructs and instruments along with the correlations between the individual constructs and innovation are presented in the last two columns.

\section{Validity}

Evidence of validity of both instruments was based on confirmatory factor analyses. The HRP scale showed an acceptable fit in a tested confirmatory factor model, in a seven-factor model (training and development, compensation and rewards, PA, supervisor support, staffing, diversity management, and communication and information sharing). Although the perfect model fit was not achieved, with a maximum likelihood chi-square of 1192.82, the degrees of freedom (df) being 168, and $p<0.001$, as is the norm with large samples (Vandenberg \& Lance, 2000), the less stringent test revealed a satisfactory fit. The TLI of 0.963 was substantially larger than the cut-off score of 0.900 (satisfactory fit), a CFI of 0.931 was also considerably greater than the cutoff score of 0.900 (satisfactory fit) and a RMSEA of 0.044 was lower than the cut-off score of 0.050 (good fit), with a $90 \%$ confidence interval from 0.042 to 0.047 .

As specified in the method section, the declared variance was reported only as a proof of validity. The single factor declared $52.775 \%$ of the variance in the instrument, with only one item with a loading of less than 0.5. This confirms the unidimensionality of the instrument, as reported by De Jong and Den Hartog (2010).

\section{Correlation and regression analyses}

The correlations between the individual HRP constructs and innovation are presented in Table 1 . Table 2 presents the results pertaining to the relationship between HRPs and innovation.

In column 2, depicting the relationship between HRPs and innovation, it can be reported that $R=0.319$. The correlation coefficient was statistically significant. When considering the practical significance, $R$ is 'medium'. Considering the coefficient of determination, $10.2 \%$ of the variance in IWB is declared by HRPs. It is, therefore, practically insignificant.
The results of the regression are presented in column 3 where all the individual subscales are regressed to predict innovation. The 'Enter' option in SPSS was selected for this analysis. It can be reported that $R_{\text {adjusted }}^{2}=0.107$, depicting the relationship between all subscales of the HRP scale and innovation. The correlation coefficients were statistically significant. When considering the practical significance, $R_{\text {adjusted }}^{2}$ is 'small'. Using all the subscales of the HRP scale allowed for $10.7 \%$ of the variance in IWB to be declared.

In order to identify those individual HRPs which contribute uniquely and significantly to predicting innovation, 'Stepwise' regressions were performed, using the 'Stepwise' option in SPSS. From column 4, it can be read that staffing, training and development, communication and information sharing, compensation and rewards, and supervisor support (listed in descending order of influence on innovation) of the HRP scale are the individual HRPs that influence IWB uniquely and significantly. Considering these important predictors, it is evident that PA and diversity management are neither common nor unique predictors of innovation.

While the importance of PA as an antecedent to innovation relative to an array of individual HRPs among employees has been established, it is, however, not clear whether the individual HRPs are an effective driver of innovation in all organisations. The intention of the following analysis is to investigate the importance of $\mathrm{PA}$ as an antecedent to innovation, relative to an array of individual HRPs within specific South African organisations.

Table 3 presents three columns (column 3 to column 5) of results for the individual samples drawn from the 53 organisations. In column 3 , the correlation coefficients are presented for the HRPs as a single construct and innovation. The results of the regression, where all the individual HRP subscales are regressed to predict innovation, are presented in column 4 . Column 5 presents the results where the individual HRP subscales that contribute uniquely and significantly to predicting innovation are identified. As it is not viable to present data for all 53 organisations in one table, a small section is 
presented here. However, Table 3 is followed by a comprehensive summary of the complete table.

In column 2, depicting the relationship between HRPs and innovation, measured per organisation, it can be reported that all organisations displayed statistically significant coefficients between the HRP scale and IWB, with $p<0.01$ and $p<0.05$. The average coefficient for all 53 organisations was 0.311 . In total, $7 / 53(13 \%)$ of the coefficients is deemed as being of high practical significance $(R>0.5), 25 / 53(47 \%)$ of the coefficients is deemed as being of moderate practical significance $(R>0.3)$ and $21 / 53(40 \%)$ of the coefficients is deemed as being of low practical significance $(R>0.1)$.

When considering the results with regard to the practical significance of the coefficients between HRPs and IWB, there is high practical significance in a smaller proportion (13\%) of organisations when the HRP scale total scores correlated with innovation (Figure 1).

In column 3, the results of the regression are presented where all the individual subscales of the HRP scale are regressed to predict innovation at organisational level. The 'Enter' option in SPSS was selected for this analysis. It can be reported that all organisations displayed statistically significant coefficients between HRPs and IWB, with $p<0.01$. The average coefficient was 0.163 . In total, $3 / 53$ $(6 \%)$ of the coefficients is deemed as being of high practical significance, $5 / 53(9 \%)$ of the coefficients is deemed as being of moderate practical significance and 45/53 (85\%) of the coefficients is deemed as being of low practical significance.

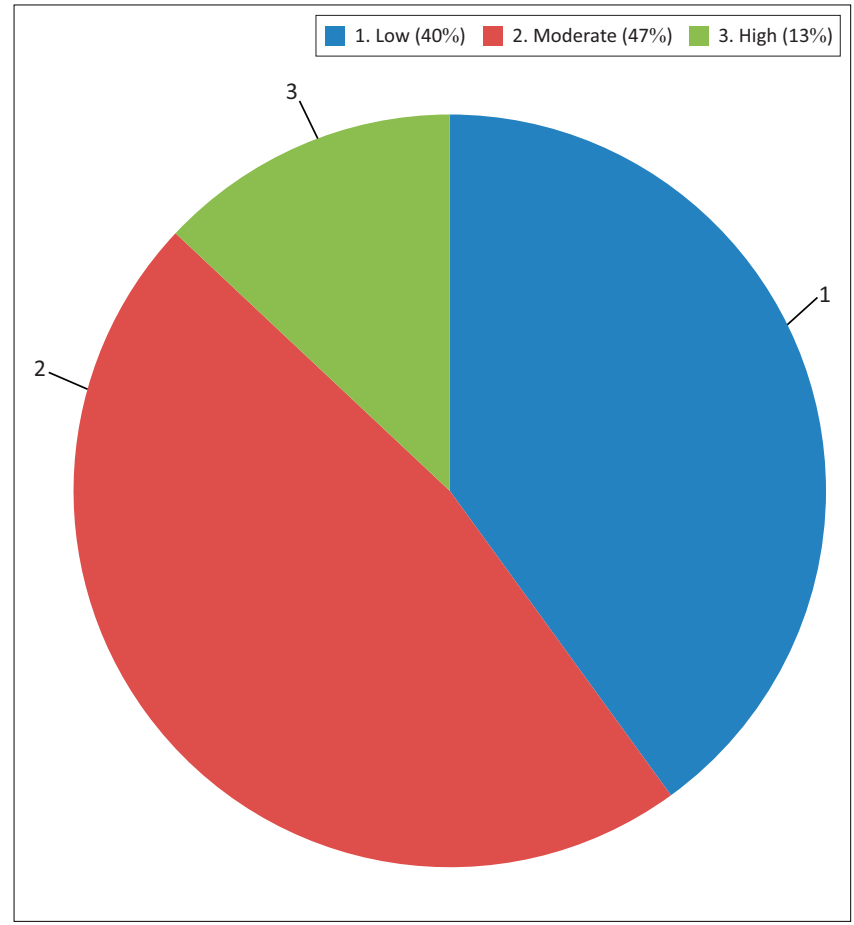

IWB, innovative work behaviour.

FIGURE 1: Practical significance of the correlation coefficients between human resource practices and innovation across organisations.
When considering the results with regard to the practical significance of the coefficients between HRPs and IWB, there is high practical significance in a smaller proportion $(6 \%)$ of organisations when all the individual subscales of the HRP scale correlate with innovation (Figure 2). The low IWB coefficients, in majority of the organisations, suggest that other factors must drive innovation.

Comparing the results in column 3 and column 4, it seems that following the correlation approach to calculate the coefficients between HRPs (as a single construct) and innovation yielded better results than the use of the regression approach in which all the individual subscales of the HRP scale are regressed to predict innovation. The relationship when using the HRPs as a single construct was larger than when using all the individual subscales of the HRP scale. This suggests both that HRP as a single construct is a better predictor of innovation and that a higher-level latent construct (which informs the total scores rather than the individual items) is responsible for the declared covariance.

'Stepwise' regressions using the 'Stepwise' option in SPSS were performed in column 4 in order to identify the individual HRP subscales which contribute uniquely and significantly to predict innovation at organisational level. This analysis served to test a hypothesis on the relative importance of PA across organisations, but more specifically, to find patterns amongst the HRP subscales which predict innovation. This was important to gain statistics on testing hypotheses on the universalistic and configurational perspectives of HRPs. It can be reported that all organisations displayed statistically

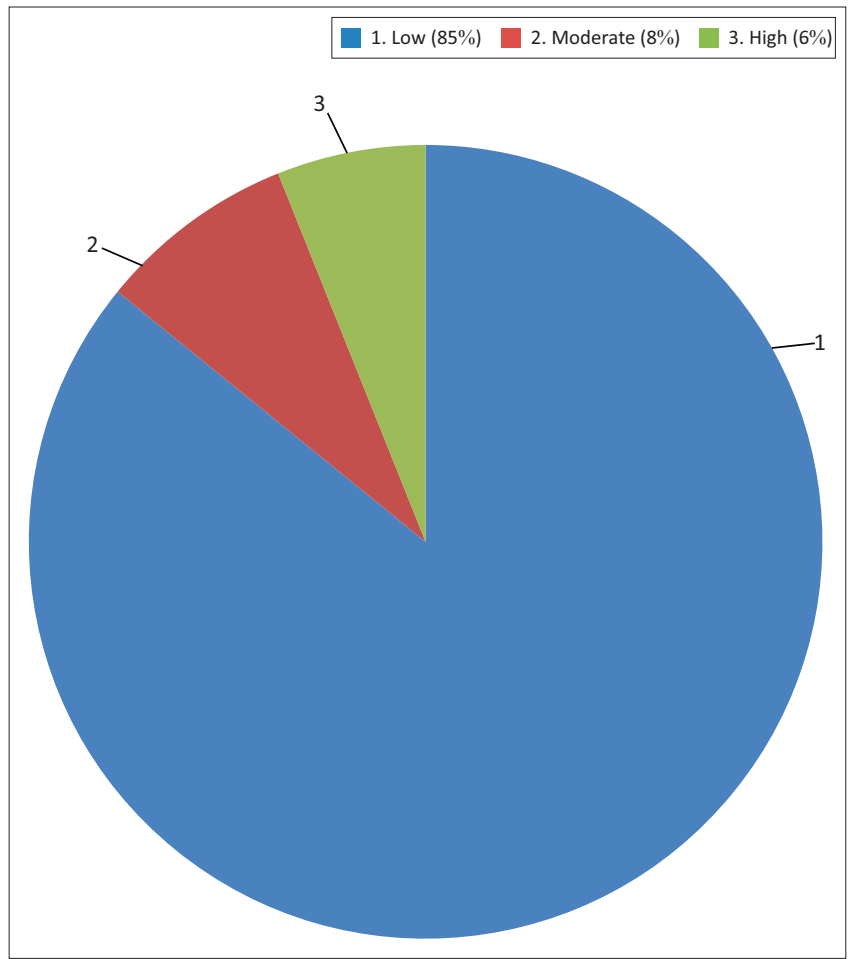

IWB, innovative work behaviour.

FIGURE 2: Practical significance of the regression coefficients between all subscales of the human resource practice scale and innovation across organisations. 
significant coefficients between the individual HRP subscales and IWB, with $p<0.01$. The average coefficient was 0.216 . In total, $2 / 45$ (4\%) of the coefficients is deemed as being of high practical significance, $8 / 45(18 \%)$ of the coefficients is deemed as being of moderate practical significance and 35/45 (78\%) of the coefficients is deemed as being of low practical significance, while there is missing data for eight organisations (organisations 4, 13, 24, 29, 39, 44, 47 and 53). The chains for the optimal models per organisation include 35 models with one variable, eight with two variables, one with three variables and one with five variables. Organisation 38 had the most variables (five) in its optimal model. The most common subscales were supervisor support and staffing, as these items appear in 11 of the 45 models. The next most common subscales were training and development, and PA, as these appear in 10 of the models, followed by compensation and rewards that appears in six of the models. Communication and information sharing was the least common variable as it appears in only five of the models. To detect evidence of sequences in the subscales predicting innovation, the twovariable models were analysed further. Repeating patterns occurred in $3 / 8$ (38\%) cases with two-variable models (supervisor support and diversity management).

\section{Discussion}

As stated earlier, no consensus on the particular practices that drive innovation is available. Also, as stated before, much of the HRP-innovation research is conducted primarily within the Western context. This study addresses the matter of clarity on specific drivers of innovation and contextualises the research within the South African context. Furthermore, the respondents represented the South African workforce well in as far as gender, race and age were concerned. In addition, the biographical data were closely aligned with information presented in the Quarterly Labour Force Survey publication (Statistics South Africa, 2016).

Although studies have found a link between HRPs and innovation, the research has often been slated for being single-company or single-industry driven and undertaken with relatively small samples. This study used a relatively large sample to explore the relationship both within and across organisations. The sample population consists of 3180 employees drawn from 53 organisations within South Africa, representing the private sector, parastatals and government departments.

The majority of the research has been limited to examine HRPs as a single concept rather than as individual practices in their own right. This study attempted to include several other HRPs in the model, and the focus was on the individual practices.

The results revealed that the relationship between HRPs (as a composite score) and innovation, although statistically significant, was practically insignificant. The relationship between all the individual subscales and innovation was also statistically significant but practically insignificant.
Focusing on the individual HRPs, some were more effective in predicting innovation than others. The subscales that predict IWB are staffing, training and development, communication and information sharing, compensation and rewards, and supervisor support. Considering these important predictors, it is evident that PA and diversity management are neither common nor unique predictors of innovation. This is not consistent with research conducted by Dalota and Perju (2010), Jimenez-Jimenez and Sanz-Valle (2005) and Laursen and Foss (2003), who present evidence that specific HRPs, such as PA, result in innovation.

The magnitude of the correlations between PA and IWB varied from 0.647 to 0.084 . Considering the finding regarding the correlation between HRPs (as a composite score) and innovation within organisations, it can be concluded that a practically significant link was established in $60 \%$ of organisations. A statistically significant link was found in all organisations. There is low practical significance in $47 \%$ of the cases.

The magnitude of the regression coefficients between PA and IWB varied from 0.649 to 0.004 . Considering the finding in which all the individual HRP subscales were regressed to predict innovation within organisations, it can be concluded that a practically significant link was established in $14 \%$ of organisations. However, a statistically significant link was found in all organisations. In a larger proportion of organisations ( $85 \%$ of the cases), there is low practical significance. The low IWB coefficients in majority of organisations suggest that other factors must drive innovation. Focusing on the individual HRP subscales at organisational level, some were more effective in predicting innovation than others. It is evident that two (supervisor support and staffing) out of the seven subscales are common predictors. These elements are the primary drivers of innovation. Therefore, should HRPs be the primary mechanism used to drive innovation in an organisation, focus should be placed on these abovementioned aspects.

Considering the finding regarding the importance of PA compared to other HRPs, it can be concluded that PA was a unique and significant predictor in 10 of the 53 organisations. However, PA was the dominant antecedent in eight of the 53 organisations. The results also show that PA is the second most important driver of innovation in comparison with the other HRPs, while supervisor support and staffing have the most significant influence on innovation within organisations. Although PA plays a less important role in influencing innovation within an organisation, it is evident that supervisor support and staffing play a much larger role in driving innovation at organisational level. This places the relative importance of PA amongst other HRPs in perspective.

It seems that the use of the correlation approach yielded better results than the use of the regression approach. The relationship was larger when using HRPs as a total score, which is in line with the research conducted by Jimenez-Jimenez and 
Sanz-Valle (2005) and suggests that HRP as a total score is a better predictor of innovation and also that the total scores, rather than a latent construct, are responsible for the declared variance.

Support for the universalistic perspective was lacking in the correlation coefficients that were reported for HRP as a single construct and innovation behaviour per organisation. No consistency was found within organisations. The results of the regression analysis, where all the individual HRP subscales are regressed to predict innovation, also do not support the universalistic perspective. The results were inconsistent, and there were large variations between organisations.

Evidence supportive of the configurational perspective was limited, and no conclusive evidence of this was found as no specific sequences apply to all 53 organisations. The results of the regression analysis, where all the individual HRP subscales are regressed to predict innovation, show that there is partial support for the configurational perspective, as repeating patterns occur in $38 \%$ of the cases. This percentage is low. Configurational fit could not, therefore, be fully supported as it is not applicable to all organisations.

As stated earlier, no test for the contingency fit was performed as data on the strategic positions of the different organisations were not collected in order to perform an analysis. It is interesting to note that the findings in South Africa in some regards are quite similar to those in the Western context, and in other cases they are quite different.

\section{Theoretical implications}

This study contributes to academic literature and theory on the HRPs and innovation relationship within South Africa, both within organisations and among employees. The research reveals that HRPs are a driver of innovation, but that it accounts for approximately $10 \%$ of the variance in innovation when considering the sample of employees. The subscales of the HRP scale which drive innovation have been specified. Furthermore, the importance and relative importance of PA as an antecedent to innovation in the workplace has been established. It has also been established that there are other HRPs that have a far more significant influence on innovation than PA has.

Focusing on the HRP-innovation link within organisations, this research demonstrates that PA is a driver of innovation at organisational level, but only in some organisations. A high practically significant HRP-innovation link was established in $13 \%$ of organisations. The subscales of the HRP scale which drive innovation have been specified. These were, however, found in only some organisations. To complicate matters further, it was found that the composite score of HRPs predicts innovation better than the individual subscales. This warrants further research on the psychometric properties of the HRP scale. Moreover, the absolute importance of PA and other HRPs, and its importance as an antecedent to innovation in the workplace, has been established. It has also been established that there are other HRPs that have a far more significant influence on innovation than PA has at organisational level. This positioning of PA amongst other HRPs is a valuable contribution to the body of knowledge. Considering the applicability of the human resource models (universalistic or configurational perspective), it can be reported that there is no support for the universalistic perspective as no uniformity was found within organisations. However, there is some support for the configurational perspective as repeating patterns were found in the twovariable models, but the configurational fit could not be fully supported as no explicit patterns apply to all 53 organisations.

\section{Practical implications}

The outcomes of the study shall benefit all interested parties and support managers and practitioners in focusing on the specific HRPs that significantly enhance innovation. Furthermore, the magnitude of the relationship has been quantified, and the attention of practitioners is drawn to the relative role of HRPs as predictors of innovation within organisations. Considering these important predictors, it is apparent that PA and diversity management are neither common nor unique predictors of innovation.

Focusing interventions on the identified aspects will enable managers and practitioners to improve their existing human resource systems significantly, aligning them to enhance innovation. This, however, comes with a warning as, although there is some commonality, it does not apply universally. Additionally, the magnitude of the HRP-innovation relationship has been quantified across organisations. Again, this differed widely across organisations as there are large variations between the coefficients. In very few organisations, PA is a practically significant driver of innovation. The attention of practitioners is thus also drawn to the relative role of PA as a predictor of innovation within organisations, relative to other HRPs.

Although this study has provided confirmation that PA has a role in influencing innovation within an organisation, it is evident that supervisor support and staffing have a much greater role in driving innovation at organisational level. It is, therefore, recommended that practitioners should focus on supervisor support and staffing, as opposed to PA or the other HRPs, and that this shift in emphasis might be at the source of innovation in organisations. These data would allow managers to enhance innovation behaviour and increase competitive advantage accordingly.

\section{Limitations and recommendations}

This study has a few limitations that are noteworthy. Firstly, the research design is cross-sectional in nature. Cross-sectional studies are executed at a particular point in time and offer no indication of the sequence of events, thus making it difficult to infer causality (Levin, 2006) from the study. However, an experimental or longitudinal research design is suggested to 
circumvent the restrictions posed by a cross-sectional design. Secondly, the exclusive utilisation of respondents' perceptions posed a restriction. The results may have been more explanatory had managers been incorporated into the reporting or had organisational statistics, such as registered patents, been utilised. Multi-source and multi-method research is proposed. Thirdly, the analysis was performed per organisation, and a sector analysis was excluded because of the total number of organisations per sector being considered unsatisfactory for statistical analysis. It can be anticipated that the unique sequences of items that predict innovation per organisation are confined to particular sectors in South Africa, and research in this regard is therefore suggested. Fourthly, CFA was used as the only method to confirm the validity of the HRP scale. Confirmatory factor analysis is not the most stringent method for confirming discriminant validity as a stand-alone assessment; it is therefore suggested that exploratory factor analysis should be used in conjunction with CFA (Farrell \& Rudd, 2009). Lastly, the contingency model validation was impossible as data on the strategy of organisations were not gathered, which posed a further restriction. Future researchers are encouraged to gather data on the present strategic position of organisations to be able to assess the applicability of all three models.

\section{Conclusion}

The objective of the study was to examine the importance of PA as an antecedent to innovation relative to other HRPs. The results showed that other HRPs, specifically supervisor support and staffing, played a much bigger role than PA in driving innovation of individuals, also across organisations. This specifies the relative importance of PA amongst other HRPs. Managers, human resource practitioners and researchers can now use data-driven evidence to select specific HRPs which significantly enhance innovation among employees and across organisations.

\section{Acknowledgements Competing interests}

The authors declare that they have no financial or personal relationships that may have inappropriately influenced them in writing this article.

\section{Authors' contributions}

N.G.M. was the main author of the article. R.S. was the supervisor of N.G.M and the co-author of the article.

\section{Funding information}

This research received no specific grant from any funding agency in the public, commercial or not-for-profit sector.

\section{Data availability statement}

Quantitative data were used in this study, and these data are available on written request.

\section{Disclaimer}

The views and opinions expressed in this article are those of the authors and do not necessarily reflect the official policy or position of any affiliated agency of the authors.

\section{References}

Abbaspour, P. (2015). Effect of strategic orientation and HRM strategies on organisational strategic performance: Examining mediating role of strategic learning and innovation. An International Peer-Reviewed Journal (Trends in Life Sciences), 4(4), 125-132.

Ahmed, I., Mohammad, S.K., \& Islam, T. (2013). The relationship between perceived fairness in performance appraisal and organisational citizenship behaviour in the fairness in performance appraisal and organisational citizenship behaviour in the banking sector of Pakistan: The mediating role of organisational
International Journal of Management and Innovation, 5(2), 75-88.

Aktharsha, U.S., \& Sengottuvel, A. (2016). Knowledge sharing behaviour and innovation capability: HRM practices in hospitals. SCMS Journal of Indian innovation capability: HRM
Management, 13(1), 118-130.

Al-Bahussin, S.A., \& El-Garaihy, W.H. (2013). The impact of human resource management practices, organisational culture, organisational innovation and knowledge management on organisational performance in large Saudi organisations: Structural equation modelling with conceptual framework. International Journal of Business and Management, 8(22), 1-19. https://doi.org/10.5539/ijbm.v8n22p1

Aryanto, R., Fontana, A., \& Afiff, A.Z. (2015). Strategic human resource management, innovation capability and performance: An empirical study in Indonesia software industry. Procedia - Social and Behavioural Sciences, 211(1), 874-879. https:// doi.org/10.1016/j.sbspro.2015.11.115

Awang, Z. (2012). Structural equation modelling using AMOS graphic (1st edn.). Shah Alam: Universiti Teknologi MARA Press.

Bateman, T.S., \& Crant, J.M. (1993). The proactive component of organisational behaviour: A measure that correlates. Journal of Organisational Behaviour, 14(2), 103-118. https://doi.org/10.1002/job.4030140202

Becker, B.E., \& Huselid, M.A. (1998). High performance work systems and firm performance: A synthesis of research and managerial implications. Research in Personnel and Human Resource Management, 16, 53-101.

Bryman, A.D. (2012). Social research methods (4th edn.). New York: Oxford University Press.

Cascio, W.F. (2010). Managing human resources: Productivity, quality of work life, profits (8th edn.). New York: McGraw-Hill Irwin.

Ceylan, C. (2013). Commitment-based HR practices, different types of innovation activities and firm innovation performance. International Journal of Human Resource Management, 24(1), 208-226. https://doi.org/10.1080/09585192.2012. 680601

Chang, S., Gong, Y., \& Shum C. (2011). Promoting innovation in hospitality companies through human resource management practices. International Journal of Hospitality Management, 30(4), 812-818. https://doi.org/10.1016/j.ijhm.2011.01.001

Chen, C., \& Huang, J. (2009). Strategic human resource practices and innovation performance - The mediating role of knowledge management capacity. Journal of Business Research, 62(1), 104-114. https://doi.org/10.1016/j. jbusres.2007.11.016

Claus, L. (2003). Similarities and differences in human resource management in the European Union. Thunderbird International Business Review, 45(1), 729-756. https://doi.org/10.1002/tie.10100

Cohen, J. (1988). Statistical power analysis for the behavioural sciences (2nd edn.). Hillsdale, NJ: Lawrence Erlbaum Associates.

Cooke, F., \& Saini, D. (2010). (How) Does the HR strategy support an innovation oriented business strategy? An investigation of institutional context and organisational practices in Indian firms. Human Resource Management, 49(3), 377-400. https://doi.org/10.1002/hrm.20356

Dalota, M. (2013). SMS's innovation and human resources management. Romanian Economic and Business Review, 8(3.1), 203-210.

Dalota, M., \& Perju, A. (2010). Human resource management and the company's innovation. Romanian Economic and Business Review, 5(4), 122-131.

De Jong, J., \& Den Hartog, D. (2010). Measuring innovative work behaviour. Creativity and Innovation Management, 19(1), 23-36. https://doi.org/10.1111/j.1467 8691.2010.00547.x

Delery, J.E., \& Doty, D.H. (1996). Modes of theorising in strategic human resource management: Tests of universalistic, contingency, and configurational performance predictions. Academy of Management Journal, 39(4), 802-835.

Delery, J., \& Gupta, N. (2016). Human resource management practices and organisational effectiveness: Internal fit matters, Journal of Organisational Effectiveness: People and Performance, 3(2), 139-163. https://doi.org/10.1108/ JOEPP-03-2016-0028

DeNisi, A.S., \& Pritchard, R.D. (2006). Performance appraisal, performance management and improving individual performance: A motivational framework. Management and Organisation Review, 2(2), 253-277. https://doi.org/10.1111/ j.1740-8784.2006.00042.x

Edralin, D.M. (2010). Human resource management practices: Drivers for stimulating corporate entrepreneurship in large companies in the Philippines. DLSU Business \& Economics Review, 19(2), 25-41. https://doi.org/10.3860/ber.v19i2.1471 
Esu, B.B., \& Inyang, B.J. (2009). A case for performance management in the public sector in Nigeria. International Journal of Business and Management, 4(4),98105. https://doi.org/10.5539/ijbm.v4n4p98

Farrell, A.M., \& Rudd, J.M. (2009). Factor analysis and discriminant validity: A brief review of some practical issues. In Australia-New Zeeland Marketing Academy Conference (ANZMAC) (pp. 1-9). Melboure, Australia.

Hair, J.F., Black, W.C., Babin, B.J., \& Anderson, R.E. (2009). Multivariate data analysis (7th edn.). Upper Saddle River, NJ: Pearson Education International.

Hayton, J.C. (2005). Promoting corporate entrepreneurship through human resource management practices: A review of empirical research. Human Resource Management Review, 15(1), 21-41. https://doi.org/10.1016/j.hrmr.2005.01.003

Jeong, D.Y., \& Choi, M. (2016). The impact of high-performance work systems on firm performance: The moderating effects of the human resource function's influence. Journal of Management and Organisation, 22(3), 328-348. https://doi. org/10.1017/jmo.2015.38

Jimenez-Jimenez, D., \& Sanz-Valle, R. (2005). Innovation and human resource management fit: An empirical study. International Journal of Manpower, 26(4), management fit: An empirical study. International Journ

Katou, A.A. (2008). Innovation and human resource management: The Greek experience. Organizacija, 41(3), 81-90. https://doi.org/10.2478/v10051-008-0009-3

Katou, A.A., \& Budhwar, P.S. (2007). The effect of human resource management policies on organisational performance in Greek manufacturing firms. Thunderbird International Business Review, 49(1), 1-36. https://doi.org/10.1002/tie.20129

Keir, M.Y.A. (2016). Staff perceptions of how human resource management practices influence organisational performance: Mediating roles of organisational culture, employees' commitment and employee retention in Bahrain private universities. Doctoral dissertation. Cardiff: Cardiff Metropolitan University.

Kim, D., \& Choi, Y. (2014). Social exchange model between human resource management practices and innovation in software engineering. Seoul Journal of Business, 20(2), 49-69. https://doi.org/10.35152/snusjb.2014.20.2.003

Laursen, K., \& Foss, N.J. (2003). New human resource management practices, complementarities and the impact on innovation performance. Cambridge Journa of Economics, 27(2), 243-263. https://doi.org/10.1093/cje/27.2.243

Le Bas, C., \& Lauzikas, M. (2009). The combination of innovation and human resource strategies: The case of information technology sector in Lithuania. Intellectual Economics, 2(6), 18-29.

Lengnick-Hall, M.L., Lengnick-Hall, C.A, Andrade, L.S., \& Drake, B. (2009). Strategic human resource management: The evolution of the field. Human Resource Management Review, 19(2009), 64-85. https://doi.org/10.1016/j.hrmr.2009.01.002

Levin, K.A. (2006). Study design III: Cross-sectional studies. Evidence-Based Dentistry, 7(1), 24-25. https://doi.org/10.1038/sj.ebd.6400375

Ling, T.C., \& Nasurdin, A.M. (2011). Human resource management practices and organisational innovation: Assessing the mediating role of knowledge management effectiveness. Electronic Journal of Knowledge Management, 9(2), 155-167.

Looise, J.K., \& Van Riemsdijk, M. (2004). Innovating organisations and HRM: A conceptual framework. Management Revue, 15(3), 277-287. https://doi org/10.5771/0935-9915-2004-3-277

Madmoli, Z. (2016). Investigating the relation between human resource management and organisational entrepreneurship: The mediating role of knowledge sharing by middle managers (Case study: Ahwaz Pipe Manufacturing Company). International Journal of Humanities and Cultural Studies, 1(2016), 2739-2751.
Maier, A., Brad, S., Nicoara, D., \& Maier, D. (2014). Innovation by developing human resources, ensuring the competitiveness and success of the organisation. Procedia resources, ensuring the competitiveness and success of the organisation. ProcediaSocial and Behaviour
sbspro.2013.12.521

Noe, R.A., Hollenbeck, J.R., Gerhart, B., \& Wright, P.M. (2008). Human resource management: Gaining a competitive advantage (6th edn.). Boston, MA: McGrawHill Irwin.

Nunnally, J.C. (1978). Psychometric theory (2nd edn.). New York: McGraw-Hill.

Nyawose, M. (2009). The relationship between human resources management practices, organisational commitment and turnover intentions amongst engineering professionals. Unpublished master's thesis. Pretoria, South Africa: University of South Africa.

Pallant, J. (2013). SPSS survival manual: A step by step guide to data analysis using IBM SPSS (5th edn.). New York: McGraw-Hill.

Peck, R., \& Devore, J.L. (2011). Statistics: The exploration and analysis of data (7th edn.). San Luis Obispo, CA: Cengage Learning.

Punch, K.F. (1998). Introduction to social research: Quantitative and qualitative approaches (1st edn.). London: Sage.

Runfeng, Y. (2011). Influence of goal orientation in performance appraisal on staff innovative behaviour: Mediating effect of innovative climate. Proceedings of the 8th International Conference on Innovation and Management (pp. 445-451). Kitakyushu, Japan: Yamaguchi University.

Statistics South Africa. (2016). Quarterly Labour Force Survey - Quarter 4: 2016 (Statistical release P0211). Retrieved from http://www.statssa.gov.za/publications/ P0211/P02114thQuarter2016.pdf.

Steyn, R. (2012). Human resource practices and employee attitudes: A study of individuals in ten South African companies. Alternation, 5(2012), 167-184.

Steyn, R., \& Grobler, A. (2014). The relationship between human resource practices and employee attitudes in a travel agency. African Journal of Hospitality, Tourism and Leisure, 3(1), 1-10.

Subramaniam, M., \& Youndt, M.A. (2005). The influence of intellectual capital on the types of innovative capabilities. Academy of Management Journal, 48(3), 450-463. https://doi.org/10.5465/amj.2005.17407911

Sun, L.Y., Aryee, S., \& Law, K.S. (2007). High-performance human resource practices, citizenship behaviour, and organisational performance: A relational perspective. Academy of Management Journal, 50(3), 558-577. https://doi.org/10.5465/ AMJ.2007.25525821

Tang, G., Wei, L.Q., Snape, E., \& Ng, Y.C. (2015). How effective human resource management promotes corporate entrepreneurship: Evidence from China. The International Journal of Human Resource Management, 26(12), 1586-1601. https://doi.org/10.1080/09585192.2014.953973

Ursachi, G., Horodnic, I.A., \& Zait, A. (2015). How reliable are measurement scales? External factors with indirect influence on reliability estimators. Procedia Economics and Finance, 20(1), 679-686. https://doi.org/10.1016/S2212 5671(15)00123-9

Vandenberg, R.J., \& Lance, C.E. (2000). A review and synthesis of the measurement invariance literature: Suggestions, practices, and recommendations for organisational research. Organisational Research Methods, 3(1), 4-70. https:// doi.org/10.1177/109442810031002

Wu, W.Y., \& Lee, F.H. (2013). The influence of commitment-based HR practices and knowledge-sharing on employees' innovation performance. African Journal of Business Management, 7(24),2381-2393. https://doi.org/10.5897/AJBM2013.6979 